\title{
First report of Melampsora dimorphospora on white willow in Pakistan
}

\author{
Aamna Ishaq ${ }^{1}$. Najam ul Sehar Afshan ${ }^{2} \cdot$ Abdul Nasir Khalid $^{1}$ \\ Received: 2 May 2018 / Accepted: 9 July 2018 / Published online: 7 August 2018 \\ (C) Società Italiana di Patologia Vegetale (S.I.Pa.V.) 2018
}

During a uredinological survey carried out in September 2012 in the Ushu valley of Swat district, Pakistan, leaves of the medicinally important tree Salix alba L. commonly known as white willow, were found to be infected with a rust fungus. Uredinia were abaxial, scattered, rounded and brownish yellow. Urediniospores were found of two different types: one type of urediniospores were observed to be subglobose, golden brown in color, $18-23 \times 18-27 \mu \mathrm{m}$ with hyaline spore walls of to $2.5 \mu \mathrm{m}$ thickness, echinulated with obscure germpores. A second type of urediniospores were found, subglobose to broadly ellipsoidal, catenulate in short chains, (22-) $27-33 \times 28-36 \mu \mathrm{m}$ with dark brown, 2.5-3.5 $\mu \mathrm{m}$ thick, verrucose spore walls, germ pores were up to 2 , tending to be equatorial. Paraphyses were numerous, intermixed, capitate to clavate, $20-26 \times 30$ $47 \mu \mathrm{m}$ with up to $4 \mu \mathrm{m}$ thick wall. Based on these morphological traits and dimorphic urediniospores, the rust was identified as Melampsora dimorphospora $\mathrm{S}$. Kaneko \& Hirats, a sample of which was deposited in LAH Herbarium (LAHAM20006) of the University of the Punjab, Lahore. It has previously been found on Salix koriyanag Kimura (Koriyananagai) from Japan (Hiratsuka et al. 1992). To the best of our knowledge, it is a new record for Pakistan.

Funding The authors are highly obliged to the Higher Education Commission (HEC) of Pakistan for funding this research.

\section{Reference}

Hiratsuka N, Sato S, Katsuya K, Kakishima M, Hiratsuka Y, Kaneko S, Ono Y, Sato T, Harada Y, Hiratsuka T, Nakayama K (1992) The rust flora of Japan. Tsukuba Shuppankai, Takezono, Ibaraki, 1205 pages

Electronic supplementary material The online version of this article (https://doi.org/10.1007/s42161-018-0147-2) contains supplementary material, which is available to authorized users.

Aamna Ishaq

aamna_ishaq@yahoo.com

1 Department of Botany, Faculty of Life Sciences, University of the Punjab, Quaid-e-Azam Campus, Lahore, Pakistan

2 Centre for Undergraduate Studies, Faculty of Science, University of the Punjab, Quaid-e-Azam Campus, Lahore, Pakistan 